\title{
Effectiveness of Rhythmic Breathing Exercise on Postoperative Pain among Patients Undergone Major Abdominal Surgery in MGMCRI at Puducherry, India
}

\author{
V Subakeerthi $^{1}$, E Finny Moses ${ }^{2}$
}

\begin{abstract}
Background and objective: Management of postoperative pain is one of the important concerns of medical team in order to promote trust, comfort and reduce pain. Hence this study was undertaken to assess the effectiveness of rhythmic breathing exercise on postoperative pain among patients undergone major abdominal surgery.

Materials and methods: The study was a quantitative research approach and pre experimental (one group pre-test and post-test) design, was adopted. Thirty patients who had undergone major abdominal surgery were selected from MGMCRI at Puducherry by using purposive sampling technique.

Results: The pre-test and post-test mean value of pain level was 7.83 with standard deviation of 0.95 and 5.70 with standard deviation 0.84 , respectively. The obtained $p$ value which was highly significant at $p<0.001$.

Conclusion: Hence the result showed that rhythmic breathing exercise was highly effective in reducing postoperative pain among patients undergone major abdominal surgery.

Keywords: Effectiveness, Patients undergone major abdominal surgery, Postoperative pain, Rhythmic breathing exercise.

Pondicherry Journal of Nursing (2019): 10.5005/jp-journals-10084-12107
\end{abstract}

\section{INTRODUCTION}

Pain is a biological alarm. In case of postoperative patients, the intensity of pain depends upon the site of surgery which has a profound effect upon the degree of postoperative pain a patient may suffer. The pain perceived by the patients undergone surgery on the thorax and upper abdomen are more painful compared to the surgery on the lower abdomen which, in turn are more painful than peripheral operation on the limbs. Pain assessment has been called the fifth vital sign joining temperature, pulse, respiration and blood pressure. Pain accompanying surgery is one of the example of acute pain but purely understood and not well managed. ${ }^{1-5}$

Effective pain management is an art of giving a right medicine at the right time. It is the combination of both pharmacological and nonpharmacological approaches that together give the individual the greatest possible degree of comfort for the longest possible time. ${ }^{6-10}$

Rhythmic breathing exercise is a relaxation technique, which is done in the same way as deep breathing exercise, but it is timed to the rhythm of one's heartbeat. It enhances oxygen supply, re-establishes and improves the body's own natural rhythm and can bring good change in both physical and mental state. Breathing as a method of relaxation is directly linked with the autonomic nervous system which control physiological arouse of human being. ${ }^{11-13}$

\section{Need for the Study}

The incidence of abdominal diseases and surgeries like the gastrointestinal, biliary, and liver surgeries, splenectomy, herniorrhaphy, appendectomy, surgery on great vessels of trunk are increasing in present days. ${ }^{14,15}$

Pain is a subjective experience in health and illness. For a hospitalized patient, pain anticipated may be an actual problem. All
${ }^{1}$ Department of Community Health Nursing, Kasturba Gandhi Nursing College, Sri Balaji Vidyapeeth, Puducherry, India

${ }^{2}$ Department of Medical Surgical Nursing, Kasturba Gandhi Nursing College, Sri Balaji Vidyapeeth, Puducherry, India

Corresponding Author: V Subakeerthi, Department of Community Health Nursing, Kasturba Gandhi Nursing College, Sri Balaji Vidyapeeth, Puducherry, India, Phone: +91 9841726659, e-mail: vsubakeerthi@ gmail.com

How to cite this article: Subakeerthi V, Moses EF. Effectiveness of Rhythmic Breathing Exercise on Postoperative Pain among Patients Undergone Major Abdominal Surgery in MGMCRI at Puducherry, India. Pon J Nurs 2019;12(1):5-7.

Source of support: Nil

Conflict of interest: None

medical and surgical interventions are associated with pain. Patient's responses to pain depends on individual perception of the pain influenced by past experience and sociocultural factors, etc. ${ }^{24-29}$ The pain after surgery can help recovery by increasing the body's response to surgical stress, tissue breakdown, coagulation and fluid retention. Pain also interferes with appetite and can lead to avoidance of family, social, recreational and employment activities. ${ }^{16-19}$

Relaxation techniques stimulate the process of relaxation in the body. It is the important element of stress management, reduces the muscle tension, decreases blood pressure, regulates the heart and breath rates and promotes the comfort of the body. It is proved that it will be very effective when it is done continuously. ${ }^{20-23}$

Since postoperative patients is more common among the surgical patients. Management of pain after surgery is one of the most important concern of health care for providing comfort and 
Table 1: Frequency and percentage distribution of pain level on before and after rhythmic breathing exercise among postoperative patients undergone major abdominal surgery $(n=30)$

\begin{tabular}{lllllll}
\hline & & \multicolumn{2}{c}{ Pre-test } & & \multicolumn{2}{c}{ Post-test } \\
\cline { 3 - 4 } S. no. & Level of pain & Percentage & Frequency $(n)$ & & Percentage & Frequency $(N)$ \\
\hline 1 & Moderate pain & 2 & 6.7 & & 25 & 83.3 \\
2 & Severe pain & 28 & 93.3 & 5 & 16.7 \\
\hline
\end{tabular}

sleep and to promote trust after surgery and to prevent complication that may lead to intense pain, surgical stress. For this purpose the researcher has opted rhythmic breathing exercise for reducing the level of pain in patients undergone major abdominal surgery.

\section{Objectives}

- To assess the level of postoperative pain among patients undergone major abdominal surgery.

- To assess the effectiveness of rhythmic breathing exercise on postoperative pain among patients undergone major abdominal surgery.

- To associate the level of postoperative pain in patients with major abdominal surgery with their selected demographic variables.

\section{Materials and Methods}

The study was adopted with quantitative research approach and pre-experimental (one group pre-test and post-test) design, was adopted. Thirty patients undergone major abdominal surgery were selected from MGMCRI at Puducherry, by using purposive sampling technique and the data were collected by using demographic variables. Every day 6 patient who satisfied inclusion criteria were selected for 5 days, and postoperative pain levels were assessed and rhythmic breathing exercises were taught to the patients. The patients were asked to do rhythmic breathing exercise twice daily. The assessment of postoperative pain level was done by using numerical rating scale both in pre-test and post-test. The data were analyzed in terms of both descriptive and inferential statistics.

\section{Results}

Table 1 shows distribution of pre-test and post-test level of pain before and after rhythmic breathing exercise among postoperative patients undergone major abdominal surgery. In pre-test out of 30 samples, most of the patients $2(6.7 \%)$ had moderate pain level and $28(93.3 \%)$ had severe pain. In post-test most of the patients 2 (6.7\%) had moderate pain level and 28 (93.3\%) had severe pain. In post-test 25 (83.3\%) of the patients had moderate pain level, 5 (16.75) of patients had severe pain level. It showed that rhythmic breathing exercise was highly effective in reduction of postoperative pain among patients undergone major abdominal surgery. Hence stated hypothesis $(\mathrm{H} 1)$ was accepted.

Table 2: Comparison of the mean pre-test and post-test pain level score of patients undergone major abdominal surgery $(n=30)$

\begin{tabular}{lllll}
\hline & & \multicolumn{3}{c}{ Wilcoxon signed } \\
Pain level & Mean & Std. deviation & rank test & p value \\
\hline Pre test & 7.83 & 0.95 & -5.106 & $0.000^{* *}$ \\
Post test & 5.70 & & & \\
\hline
\end{tabular}

\footnotetext{
**Highly statistically significant $p<0.001$
}

Table 2 shows that in the pre-test and post-test mean postoperative pain level score of patients undergone major abdominal surgery. The subject mean value was 7.83 with standard deviation of 0.95 whereas after rhythmic breathing exercise the mean score was decreased 5.70 with standard deviation 0.84 the improvement was statistically tested by paired $t$ test which was found to be highly statistically significant at $p<0.001$ level it indicates that rhythmic breathing exercise was effective in reduction of postoperative pain level among patients undergone major abdominal surgery.

\section{ConCLUSION}

Prevalence of postoperative pain is most common among patients undergone major abdominal surgery. The treatment modalities shows some side effects. This study revealed that rhythmic breathing exercise which show reduction in postoperative pain and improves level of physical functioning. As rhythmic breathing exercise it does not show any side effects which is also effective and easily can do and improves quality of life among patients undergone major abdominal surgery. This study findings shows that the regular practice of rhythmic breathing exercise helps to reduce postoperative pain level among patients undergone major abdominal surgery.

\section{Declaration of Patient Consent}

The authors certify that they have obtained all appropriate patient consent forms. In the form the patients have their consent for their images and other clinical information to be reported in the journal. Patients understand that their names and initials will not be published and due efforts will be made to conceal their identity, but anonymity cannot be guaranteed.

\section{References}

1. Basavantappa BT. Medical Surgical Nursing, 3rd ed. New Delhi: Jaypee Brothers Medical Publishers (P) Ltd, New Delhi; 2015. pp. 135-227.

2. Brennan F, Carr DB, Cousins M. Pain management: a fundamental human right. Anesth Analg 2007;105(1):205-221. DOI: 10.1213/01. ane.0000268145.52345.55.

3. Kehlet $\mathrm{H}$, Holte K. Effect of postoperative analgesia on surgical outcome. Br J Anaesth 2001;87(1):62-72. DOI: 10.1093/bja/87.1.62.

4. Kehlet $\mathrm{H}$, Jensen $T S$, Woolf $C J$. Persistent postsurgical pain: risk factors and prevention. Lancet 2006;367(9522):1618-1625. DOI: 10.1016/ S0140-6736(06)68700-X.

5. American Society of Anesthesiologists Task Force on Acute Pain Management. Practice guidelines for acute pain management in the perioperative setting: an updated report by the American Society of AnesthesiologistsTaskForceon AcutePain Management. Anesthesiology 2012 Feb;116(2):248-273. DOI: 10.1097/ALN.0b013e31823c1030.

6. Smeltzer SC, Bare BG, Hinkle JL, Cheever KH. Cheever Brunner \& Suddarth's Textbook of Medical - Surgical Nursing, 11th ed., New Delhi: Wolters Kulwer (India) Pvt Ltd; 2008. p. 241.

7. Russell RCG, Williams NS, Bulstrode CJK. ed. Bailey \& Love's, Short Practice of Surgery, 24th ed. Bulstrode Publication; 2004. p. 1439.

8. Brookman C, Kumar K, Wu CL. Burn Pain. In: Benzon HMD. ed. Practical Management of Pain, 5th ed. China: Elsevier; 2014. 
9. American Academy of Pain Management. Accredited pain programs. 2011. [Accessed April 8, 2011] https://members.aapainmanage.org/ aapmssa/censsacustlkup.query_page.

10. Apfelbaum JL, Chen C, Mehta SS, Gan TJ. Postoperative pain experience: results from a national survey suggest postoperative pain continues to be undermanaged. Anesth Analg 2003;97(2):534-540. DOI: 10.1213/01.ane.0000068822.10113.9e.

11. Brown RP, Gerbarg PL. The Healing Power of the Breath. Boston: Shambhala Publications, Inc; 2012.

12. Jennifer $C$. The effect of rhythmic breathing on blood pressure in hypertensive adults. J Undergrad Res 2000;1:78-98.

13. Pal GK, Velkumary S, Madanmohan T. Effect of short-term practice of breathing exercises on autonomic functions in normal human volunteers. Indian J Med Res 2004;120:115-121.

14. Abdominal surgery. [online]. Available from: http://en.wikipedia.org/ wiki/Abdominal_surgery.

15. Statistics on surgical procedures in the US. [online]. Available from: http://www.ncbi.nlm.gov/.

16. Caumo W, Schmidt AP, Schneider CN, Bergmann J, Iwamoto CW, Adamatti LC, et al. Risk factors for postoperative anxiety in adults. Anaesthesia 2001;56:720-728. DOI: 10.1046/j.1365-2044.2001.01842.x.

17. Pereira EDB, Fernandes ALG, da Silva Anção $M$, de Araúja Pereres C, Atallah AN, Faresin SM. Prospective assessment of the risk of postoperative pulmonary complications in patients submitted to upper abdominal surgery. Sao Paulo Med J 1999;117(4):151-160.

18. Kanat F, Golcuk A, Teke T, Golcuk M. Risk factors for postoperative pulmonary complications in upper abdominal surgery. ANZ J Surg 2007;77(3):135-141. DOI: 10.1111/j.1445-2197.2006.03993.x.
19. Gore DC, Jahoor F, Wolfe RR, Herndon DN. Acute response of human muscle protein to catabolic hormones. Ann Surg 1993;218(5): 679-684. DOI: 10.1097/00000658-199321850-00015.

20. Burton D, Nicholson G, Hall G. Endocrine and metabolic response to surgery. Continuing Education in Anaesthesia Critical Care \& Pain 2004;4(5):144-147.

21. Upadhyay Dhungel K, Malhotra V, Sarkar D, Prajapati R. Effect of alternate nostril breathing exercise on cardiorespiratory functions. Nepal Med Coll J 2008;10:25-27.

22. Holland $A E$, Hill $C J$, Jones $A Y$, McDonald CF. Breathing exercises for chronic obstructive pulmonary disease. Cochrane Database Syst Rev 2012;10:CD008250. DOI: 10.1002/14651858.CD008250.pub2.

23. Pal GK, Velkumary S, Madanmohan T. Effect of short-term practice of breathing exercises on autonomic functions in normal human volunteers. Indian J Med Res 2004;120:115-121.

24. Kwekkeboom KL, Gretarsdottir E. Systematic Review of Relaxation Intervention for Pain. J Nurs Scholarsh 2006;38:269-277.

25. Charlton E. The management of postoperative pain. Update Anaesth 1997;7:1-7.

26. Levin FR, Malloy BG, Hyman RB. Nursing management of postoperative pain. J Adv Nurs 2006;12(4):463-472.

27. Vallano A, Aguilera C, Arnau JM. Management of postoperative pain in abdominal surgery. Br J Clin Pharmacol 1999;47(6):667-673. DOI: 10.1046/j.1365-2125.1999.00962.x.

28. Edwards CL, Fillingim RB, Keefe F. Race, ethnicity and pain. Pain 2001;94:133-137.

29. Helman CG. Culture, health and illness, 5th ed. London: Hodder Arnold, 2007. 